\title{
Comparison of the next-generation sequencing (NGS) technology with culture methods in the diagnosis of bacterial and fungal infections
}

\author{
Peixin Chen ${ }^{1,2}$, Wenwen Sun $^{3}$, Yayi $\mathrm{He}^{1}$ \\ ${ }^{1}$ Department of Medical Oncology, Shanghai Pulmonary Hospital, Tongji University Medical School Cancer Institute, Tongji University School of \\ Medicine, Shanghai, China; ${ }^{2}$ Tongji University, Shanghai, China; ${ }^{3}$ Tuberculosis Department, Shanghai Pulmonary Hospital, Shanghai, China \\ Contributions: (I) Conception and design: P Chen, Y He; (II) Administrative support: Y He, W Sun; (III) Provision of study materials or patients: Y \\ He, W Sun; (IV) Collection and assembly of data: P Chen; (V) Data analysis and interpretation: P Chen; (VI) Manuscript writing: All authors; (VII) \\ Final approval of manuscript: All authors. \\ Correspondence to: Yayi He. Department of Medical Oncology, Shanghai Pulmonary Hospital, Tongji University Medical School Cancer Institute, \\ Tongji University School of Medicine, No. 507 Zhengmin Road, Shanghai, China. Email: 2250601@qq.com.
}

\begin{abstract}
Background: Bacterial and fungal infections that caused by various kinds of pathogens are frequentlyoccurring disease all over the world. To overcome the shortcomings of traditional culture method, we have adapted next-generation sequencing (NGS) technology to identify pathogens.

Methods: In this study, clinical samples from 20 patients pre-diagnosed with bacterial and fungal infections in the Shanghai Pulmonary Hospital of Tongji University, China, were investigated retrospectively to compare the NGS with conventional "gold standard" culture methods.

Results: The detection rates of bacterial or fungal infections were 95.0\% (19/20) by NGS and 60.0\% (12/20) by culture method. There was a significant difference between the results of NGS and traditional culture method by using McNemar's $\chi^{2}$ test $(\mathrm{P}=0.008)$.

Conclusions: NGS, as an emerging diagnostic technology, shows outstanding advantages in the diagnosis of bacterial and fungal infections, and optimizes the treatment of infectious diseases. The clinical application and future development of NGS technology are worthy of expectation.
\end{abstract}

Keywords: Next-generation sequencing technology (NGS technology); culture methods; bacterial and fungal infections; diagnosis

Submitted Feb 17, 2020. Accepted for publication Jul 17, 2020.

doi: $10.21037 /$ jtd-20-930

View this article at: http://dx.doi.org/10.21037/jtd-20-930

\section{Introduction}

Bacterial infection disease, as one of the common diseases all over the world, is caused by pathogenic bacteria or conditional pathogenic bacteria.

The study of pathogenesis and pathogenicity demonstrated that bacterium could invade the blood circulation system to grow, propagate, and release bacterial toxins and other metabolites which are harmful to human cells.

There are nearly 300 species of fungi which pose substantial risks of human diseases around the world, among whom invasive candidiasis (IC) is a leading cause of mycosis-associated mortality (1). Clinically, pathogenic fungi can be divided into two parts, one is superficial mycoses which mainly invade the skin, hair and fingernail, while the other is deep fungal infection (DFI) which mostly encroach mucous membrane, deep tissues, viscera, and even lead to the systemic disseminated infections. The worldly incidence rate of fungal disease is gradually increasing, and the reasons are many. The development of medical and surgical management, including hematopoietic stem cell transplantation (HSCT), solid organ transplantation (SOT) and so on, may result in the high frequency of fungal 
healthcare-associated infections (HAIs) (2-4).

With respect to the diagnosis of bacterial or fungal infections, there are various diagnostic methods. Microbiological tests and molecular diagnostic methods are widely used for the diagnosis of clinically bacterial or fungal infections.

So far, blood culture is regarded as the current "goldstandard" method for the diagnosis of clinically bacterial or fungal infections and is still in widespread use. However, it is time-consuming, tedious and error-prone. What's more, one of the biggest limitations of conventional culture method is that not all pathogens are suitable to be cultured, which may finally result in the lower detection rate and left untreated. Disappointingly, the data showed that the overall positive rate remained at a relatively low level, about $30 \%$ to $40 \%$ (5). The data was calculated without regard to the standardized operation, adequate capacity of blood samples and high clinical suspicion of blood-stream infection.

Enzyme-linked immunosorbent assay (ELISA)-based hybridization, fluorescence-based real-time detection, liquid or solid phase microarray detection and matrix-assisted laser desorption/ionization-time of flight mass spectrometry (MALDI-TOF MS) are parts of the innovative molecular diagnostic methods of bacterial or fungal infections. Different methods mainly rely on different detection principles. For instance, Sanger sequencing and database recognition, and MALDI-TOF MS mainly base on the tremendous nucleic acids sequences of pathogens, while ELISA works effectively in accordance with the antigenantibody reactions. Similarly, these molecular methods also in the face of the limitation of detecting only a few specific pathogens $(5,6)$.

Currently, next-generation sequencing (NGS) technology has been applied in medical microbiology because of its multiple advantages in the diagnosis of bacterial or fungal infections. NGS is a novel technique that has the characteristics of high-throughput capabilities, broad applicability, accuracy and relatively rapid turnaround time. By means of identifying the nucleotides of clinical samples and comparing against the catalogue library, NGS is capable of detecting the possible causative agents (7). In recent years, several reports had illustrated that a growing number of pathogens could be discovered by NGS technology $(8,9)$.

Nowadays, infectious diseases have been a severe public health problem. An urgent, accurate detecting mean of bacterial or fungal infections is needed, not only for health care, but also for disease control and hospital management.
In this study, NGS was compared with traditional culture method so as to determine existence of bacteria or fungi from various targeted samples.

We present the following article in accordance with the Materials Design Analysis Reporting (MDAR) reporting checklist (available at http://dx.doi.org/10.21037/jtd-20-930).

\section{Methods}

\section{Patients and samples}

This study enrolled a total of 20 patients who were diagnosed with bacterial or fungal infections in tuberculosis department or tumor department at the Shanghai Pulmonary Hospital of Tongji University, China, between January and September 2019. In the whole cohort, 11 $(55.0 \%)$ were male and $9(45.0 \%)$ were female. The average age of all patients was 44.6 years. The study was conducted in accordance with the Declaration of Helsinki (as revised in 2013) and was approved by Shanghai Pulmonary Hospital (ethical number K19-158). Samples were obtained following written informed consent from all patients. All clinical samples from patients diagnosed bacterial or fungal infections were collected according to standard procedures.

\section{NGS methodology}

\section{DNA extraction}

According to the manufacturer's operational guidebook, TIANamp Micro DNA Kit (DP316, TIANGEN BIOTECH, Beijing, China) was applied to the process of DNA extraction from $300 \mu \mathrm{L}$ of different samples.

\section{Construction of DNA libraries}

By means of DNA-fragmentation, end-repair, adapterligation and PCR amplification, DNA libraries were constructed. Agilent 2100 was used for quality control of the DNA libraries. Quality qualified libraries were sequenced by BGISEQ-50 platform.

\section{Sequencing and bioinformatic analysis}

High-quality sequencing data were obtained through removing low-quality, and short reads that less than $35 \mathrm{bp}$ in length, followed by computational subtraction of human host sequences mapped to the human reference genome (hg19) using Burrows-Wheeler Alignment. After removing low-complexity reads, the remaining data were classified by simultaneously aligning to four Microbial 
Genome Databases, including viruses, bacteria, fungi, and parasites. The classification reference databases that involve 4,152 whole genome sequence of viral taxa, 3,446 bacterial genomes or scaffolds, 206 fungi related to human infection, as well as 140 parasites associated with human diseases were downloaded from NCBI (ftp://ftp.ncbi.nlm.nih.gov/ genomes/).

\section{Statistical analysis}

The statistical analyses were performed using Statistical Package for the Social Sciences (SPSS) 22.0 statistical software (IBM SPSS, Chicago, IL, USA). The fourfold table was drawn and all data were acquired including the detective rate. The McNemar's $\chi^{2}$ test for a matched fourfold table were used to compare the NGS and traditional culture results.

\section{Results}

\section{Data analysis of the clinical samples}

Clinical samples of bacterial and fungal infections were tested by NGS technology or conventional culture method. The detailed results of 20 patients who were diagnosed with bacterial and fungal infections by NGS and culture method were demonstrated in the Table 1. According to Table 1, the same patient could carry multiple pathogens by means of NGS and culture method. Hence the Table 2 lists the count of detectable pathogens numbers and classifications of clinical patients' samples. As can be seen in Table 2, 9 bacteria and 8 fungus were identified by traditional culture method. By comparison, 79 bacteria, 4 fungus and 7 viruses were identified through NGS technology. In addition, by the way of NGS, one kind of mycoplasma was identified. Overall, 88 bacteria 12 fungus and 7 viruses were detected by combining traditional culture and NGS.

The outcomes of bacterial and fungal infections via NGS and culture method in Sample 19PH10 were the same, which both showed the infection of Pseudomonas aeruginosa. In Sample 19PH14, who were also diagnosed as the infection of Pseudomonas aeruginosa by both these two means, while the infections of Mycobacterium tuberculosis complex (Mtc) so on were detected by NGS only. On one hand, Sample 19PH01 was detected to contain Massilia timonae and Mtc infections by NGS, but neither Mtc nor other infections by conventional culture methods. On the other hand, Klebsiella pneumoniae (Kp) was found in Sample
19PH15 through culture method, but not by NGS.

It is noteworthy that NGS technology has great advantages in the detection of viruses, and traditional culture method obviously fails to detect viral pathogens currently. For example, Sample 19PH02 was diagnosed with cytomegalovirus (CMV) and Epstein-Barr virus (EBV) infection by NGS.

\section{Comparison of NGS and traditional culture method}

According to Table 3, the detection rates of bacterial and fungal infections were $95.0 \%(19 / 20)$ by NGS, and $60.0 \%(12 / 20)$ by culture method. There was a significant difference between the results of NGS and traditional culture method by using McNemar's $\chi^{2}$ test $(\mathrm{P}=0.008)$.

The data demonstrated that the traditional culture method cannot fully meet the needs of clinical diagnosis. In this study, we combined NGS with traditional culture method through two ways and measured the performance of combined diagnostic test in infectious patients. The result demonstrated that the number of positive samples was 19 when the positive NGS and culture results were combined parallelly. The detective rate of parallel diagnostic test $(95 \%$, 19/20) was distinctly higher than it of merely traditional culture method in the diagnosis of infectious patients. However, the detective rate of serial diagnostic test $(60 \%$, $12 / 20$ ) was not so satisfying.

\section{Discussion}

By comparison to traditional culture method, NGS technology has distinct advantages in the diagnosis of bacterial and fungal infections $(\mathrm{P}=0.008)$, which demonstrates its outstanding clinical application. What's more, taking all types of pathogens (bacteria, fungi, viruses, mycoplasma and sporozoite) into consideration, the detectability of NGS was obviously higher than traditional culture method. According to the detective rate of parallel diagnostic test, NGS technology is suggested to combine with traditional culture method in the diagnosis of infectious patients. Hence, NGS technology can make great contributions to the process of precision medicine in infectious patients for its capacity to precisely and rapidly screen for multiple gene targets closely related to the pathogens as well as the development of drug resistance.

However, there is an urgent need to develop NGS technology so that it can be widely and fully suitable for clinical treatment and control. To start with, with regard 
Table 1 Detailed results of infectious patients' samples detected by NGS and culture method

\begin{tabular}{|c|c|c|c|c|}
\hline Sample ID & \multicolumn{2}{|l|}{ Culture } & \multicolumn{2}{|l|}{ NGS } \\
\hline 19PH01 & $N$ & $\mathrm{~N}$ & Massilia timonae, Mtc & $\mathrm{N}$ \\
\hline 19PH02 & $N$ & $\mathrm{~N}$ & $\begin{array}{c}\text { Neisseria mucosa, Neisseria flavescens, streptococcus, } \\
\text { Rothia mucilaginosa, Prevotella, HPI, Mtc }\end{array}$ & EBV, CMV \\
\hline 19PH04 & $N$ & $\mathrm{~N}$ & Mtc, Haemophilus influenzae, Haemophilus aegyptius & $\mathrm{N}$ \\
\hline 19PH05 & $K p$ & $\mathrm{~N}$ & $\begin{array}{c}\text { Rothia mucilaginosa, Rothia dentocariosa, Veillonella } \\
\text { parvula, Capnocytophaga gingivalis, Mtc, Mycoplasma } \\
\text { orale, streptococcus, actinomycetes, Capnocytophaga } \\
\text { gingivalis }\end{array}$ & $\begin{array}{l}\text { HHV-EBV, } \\
\text { HSV1 }\end{array}$ \\
\hline 19PH07 & Candida albicans & $\mathrm{N}$ & $\begin{array}{l}\text { Prevotella melaninogenicus, Rothia mucilaginosa, } \\
\text { Actinomycetes, Mtc }\end{array}$ & $\mathrm{N}$ \\
\hline 19PH08 & $\begin{array}{l}\text { Pantoea agglomerans, Ochrobactrum } \\
\text { anthropi }\end{array}$ & $\mathrm{N}$ & Mtc, Veillonella atypica Prevotella & EBV \\
\hline 19PH09 & $N$ & $\mathrm{~N}$ & Mtc, Haemophilus influenzae & $\mathrm{N}$ \\
\hline 19PH10 & Candida albicans & $\mathrm{N}$ & $\begin{array}{c}\text { Actinomyces odontolyticus, Rothia mucilaginosa, Neisseria } \\
\text { flavescens, Veillonella atypica, Prevotella salivae, Candida } \\
\text { albicans, Mtc }\end{array}$ & EBV \\
\hline 19PH11 & $N$ & $\mathrm{~N}$ & $\begin{array}{l}\text { Mtc, Prevotella melaninogenicus, Prevotella, Streptococcus } \\
\text { oralis, Fusobacterium nucleatum, Porphyromonas sordellii }\end{array}$ & $\mathrm{N}$ \\
\hline 19PH14 & $\begin{array}{c}\text { Pseudomonas aeruginosa, Candida } \\
\text { albicans }\end{array}$ & $\mathrm{N}$ & $\begin{array}{c}\text { Mtc, Candida tropicalis, Streptococcus mitis, Rothia } \\
\text { mucilaginosa, Prevotella melaninogenicus, CRAB, } \\
\text { Porphyromonas sordellii, Pseudomonas aeruginosa }\end{array}$ & $\mathrm{N}$ \\
\hline 19PH15 & $K p$ & $\mathrm{~N}$ & Mtc & $\mathrm{N}$ \\
\hline 19PH16 & Candida albicans & $\mathrm{N}$ & Mtc & $\mathrm{N}$ \\
\hline 19PH17 & Pseudomonas putida & $\mathrm{N}$ & $\begin{array}{c}\text { Mtc, Lactobacillus salivarius, Lactobacillus crispatus, } \\
\text { Veillonella parvula, Streptococcus gordonii, Rothia } \\
\text { mucilaginosa }\end{array}$ & $\mathrm{N}$ \\
\hline 19PH18 & CRE Kp, Candida albicans & $\mathrm{N}$ & Bacteria, Mtc & $\mathrm{N}$ \\
\hline 19PH19 & $N$ & $\mathrm{~N}$ & Bacteria, Mtc & $\mathrm{N}$ \\
\hline 19PH20 & $N$ & $\mathrm{~N}$ & $N$ & $\mathrm{~N}$ \\
\hline
\end{tabular}

NGS, next-generation sequencing; Mtc, Mycobacterium tuberculosis complex; N, none; Kp, Klebsiella pneumoniae; CRAB, Carbapenemresistant Acinetobacter baumannii; HPI, Haemophilus parainfluenzae; MRSA, Methicillin-resistant Staphylococcus aureus; CRE, carbapenem-resistant Enterobacteriaceae; EBV, Epstein-Barr virus; CMV, cytomegalovirus; HHV-7, Human herpesvirus 7; HSV1, Herpes simplex virus 1. 
Table 2 The count of detectable pathogens by NGS and culture methods

\begin{tabular}{lccc}
\hline \multirow{2}{*}{ Pathogens } & \multicolumn{3}{c}{ Compared methods } \\
\cline { 2 - 4 } & NGS & Culture & Total \\
\hline Bacteria (+) & 79 & 9 & 88 \\
Fungus (+) & 4 & 8 & 12 \\
Virus (+) & 7 & 0 & 7 \\
Mycoplasma (+) & 1 & 0 & 1 \\
Total & 91 & 17 & 108 \\
\hline
\end{tabular}

+ , positive. NGS, next-generation sequencing.

Table 3 Comparison of NGS and traditional culture analyses in clinical samples

\begin{tabular}{|c|c|c|c|}
\hline \multirow{2}{*}{ NGS } & \multicolumn{2}{|c|}{ Culture } & \multirow{2}{*}{ Tota } \\
\hline & + & - & \\
\hline+ & 12 & 7 & 19 \\
\hline- & 0 & 1 & 1 \\
\hline Total & 12 & 8 & 20 \\
\hline
\end{tabular}

+, positive; -, negative. NGS, next-generation sequencing.

to the software as well as hardware in NGS, there are still several problems can be improved, such as the development of the immature bioinformatics software, the supplement of the primates' reads, and the evolvement of automation. It is not only facilitating the accuracy of NGS, but also shorten the turnaround time and lower the cost, resulting in the better conformity to clinical application. In addition, it is worth further investigating and developing the standardization process to control contaminant, thus leading to the fully utilizing the power of NGS. The existence of DNA contaminants in laboratory reagents and centrifuge tubes interferes the accuracy and analysis of NGS data $(10,11)$. Multiple and easily influenced steps in NGS are main reasons for the widespread presence of these trace contaminants. The pollution of DNA may contribute to the differential outcomes between NGS and culture method as well.

The failure to distinguish the living or dead pathogens is the huge limitation of NGS technology that needs to be taken into consideration and solved imminently. Owing to this reason, NGS, as a semiquantitative technology, is unable to clearly prove the relationship between pathogens and the disease progression, thus affecting the judgement of clinical treatment efficacy. Taking all these factors into account, it is hopeful that the detective rate and the practicability of NGS could be improved through the unremitting efforts of scientists.

The reasons of the differently diagnostic results in the same infectious patients between NGS and culture method cannot be neglected. The empirical and effective treatment of antibiotics may lead to the death of specific pathogens, thus resulting in the positive outcome in NGS while the negative outcome in traditional culture method. The body normal flora in different parts of the human body is considered as another principal cause.

Our study also had some limitations. First, our study was retrospective study. Second, the sample size was small. Further study is needed to compare the detective rate between NGS and culture method.

\section{Conclusions}

In conclusion, as an emerging diagnostic technology, NGS shows outstanding advantages in the diagnosis of bacterial and fungal infections, and optimizes the treatment of infectious diseases. Regardless of its multiple and unresolved limitations, the clinical application and future development NGS technology is worthy of expectation.

\section{Acknowledgments}

Funding: This study was supported in part by a grant from National Natural Science Foundation of China (81802255), Shanghai Pujiang Program (17PJD036) and a grant from Shanghai Municipal Commission of Health and Family Planning Program (20174Y0131), National key research \& development project (2016YFC0902300), Major disease clinical skills enhancement program of three year action plan for promoting clinical skills and clinical innovation in municipal hospitals, Shanghai Shen Kang Hospital Development Center Clinical Research Plan of SHDC (16CR1001A), "Dream Tutor" Outstanding Young Talents Program (fkyq1901), key disciplines of Shanghai Pulmonary Hospital (2017ZZ02012), grant of Shanghai Science and Technology Commission (16JC1405900).

\section{Footnote}

Reporting Checklist: The authors have completed the 
Materials Design Analysis Reporting (MDAR) reporting checklist. Available at http://dx.doi.org/10.21037/jtd-20-930

Data Sharing Statement: Available at http://dx.doi. org/10.21037/jtd-20-930

Conflicts of Interest: All authors have completed the ICMJE uniform disclosure form (available at http://dx.doi. org/10.21037/jtd-20-930). The authors have no conflicts of interest to declare.

Ethical Statement: The authors are accountable for all aspects of the work in ensuring that questions related to the accuracy or integrity of any part of the work are appropriately investigated and resolved. The trial was conducted in accordance with the Declaration of Helsinki (as revised in 2013). The study was approved by Shanghai Pulmonary Hospital and informed consent was taken from all the patients (ethical number K19-158).

Open Access Statement: This is an Open Access article distributed in accordance with the Creative Commons Attribution-NonCommercial-NoDerivs 4.0 International License (CC BY-NC-ND 4.0), which permits the noncommercial replication and distribution of the article with the strict proviso that no changes or edits are made and the original work is properly cited (including links to both the formal publication through the relevant DOI and the license). See: https://creativecommons.org/licenses/by-nc-nd/4.0/.

\section{References}

1. Pfaller MA, Diekema DJ. Epidemiology of invasive candidiasis: a persistent public health problem. Clin

Cite this article as: Chen P, Sun W, He Y. Comparison of the next-generation sequencing (NGS) technology with culture methods in the diagnosis of bacterial and fungal infections. J Thorac Dis 2020;12(9):4924-4929. doi: 10.21037/jtd-20-930
Microbiol Rev 2007;20:133-63.

2. Vazquez JA, Miceli MH, Alangaden G. Invasive fungal infections in transplant recipients. Ther Adv Infect Dis 2013;1:85-105.

3. Neofytos D, Horn D, Anaissie E, et al. Epidemiology and outcome of invasive fungal infection in adult hematopoietic stem cell transplant recipients: analysis of Multicenter Prospective Antifungal Therapy (PATH) Alliance registry. Clin Infect Dis 2009;48:265-73.

4. Upton A, Kirby KA, Carpenter P, et al. Invasive aspergillosis following hematopoietic cell transplantation: outcomes and prognostic factors associated with mortality. Clin Infect Dis 2007;44:531-40.

5. Burillo A, Bouza E. Use of rapid diagnostic techniques in ICU patients with infections. BMC Infect Dis 2014;14:593.

6. Kostrzewa M, Sparbier K, Maier T, et al. MALDI-TOF MS: an upcoming tool for rapid detection of antibiotic resistance in microorganisms. Proteomics Clin Appl 2013;7:767-78.

7. Jacob HJ. Next-generation sequencing for clinical diagnostics. N Engl J Med 2013;369:1557-8.

8. Fan S, Qiao X, Liu L, et al. Next-Generation Sequencing of Cerebrospinal Fluid for the Diagnosis of Neurocysticercosis. Front Neurol 2018;9:471.

9. Wilson MR, Naccache SN, Samayoa E, et al. Actionable diagnosis of neuroleptospirosis by next-generation sequencing. N Engl J Med. 2014;370:2408-17.

10. Lusk RW. Diverse and widespread contamination evident in the unmapped depths of high throughput sequencing data. PLoS One 2014;9:e110808.

11. Salter SJ, Cox MJ, Turek EM, et al. Reagent and laboratory contamination can critically impact sequencebased microbiome analyses. BMC Biol 2014;12:87. 